\title{
Entrepreneurial Time Commitment And Risk
}

P. E. Petrakis, (Email: ppetrak@cc.uoa.gr), Athens National and Kapodistrian University, Greece

\begin{abstract}
This article examines the relationship between risk perception, risk propensity and the ideal duration of entrepreneurial commitment. Risk perception is the basic entrepreneurial characteristic, aiming to the control and avoidance of uncertainty. Related to the ideal duration of entrepreneurial commitment, risk perception leads to the development of risk propensity and perception of time. Risk perception depends on factors such as cultural idiosyncrasies, knowledge and flexibility etc, while risk propensity is being affected by external macroeconomic variables and some important personal traits. The average duration of entrepreneurial commitment depends on macro-environmental variables, cultural idiosyncrasies, personal characteristics and the specifics of the project and entrepreneurial motives. The findings of this paper have implications on both company level and macro-level and consequently have significant policy implications.
\end{abstract}

\section{INTRODUCTION}

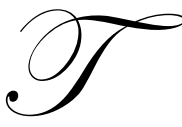

his article deals with the issue of risk and time in an entrepreneurial behaviour. Time is defined as the ideal average duration of entrepreneurial commitment. In our case risk is mainly determined by entrepreneurial risk perception and propensity.

The issue of risk is central to the study of entrepreneurial behaviour and performance. Different points of views are employed in entrepreneurial risk research agenda (Norton, Jr William, Moore 2002); opportunity recognition (Rice and Kelley 1997); opportunity evaluation (Hean Tat Keh, Maw Der Foo, Boon Chong Ling 2002); decision making and problem framing (Kahneman and Tversky 1979, Tversky and Kahneman 1981, Schneider 1992); risk propensity and cultural approval of risk (Wallach and Kogan 1964 Brockhaus 1980, Gomez- Mejia and Balkan 1989, Rowe 1997) and cognitive approaches to entrepreneurship (Palich and Barney 1995). Finally the issue of entrepreneurial alertness in relation to risk has been restated (Norton, Jr William, Moore 2002) in the light of Bayesian model.

The issue of time is a central theoretical problem of the dynamic approach to entrepreneurial behaviour (Jaques, 1997). The present article contributes to the completion of a picture of entrepreneurial traits that influence the configuration of the level and type of entrepreneurship with the perception of time as far as the optimal duration of entrepreneurial commitment. Nowadays the issue of availability of capital generally has a smaller role, and consequently the question of personal traits and social values including the entrepreneur's time dimension of risk and time has greater significance.

The question studied in this article is also related to the subject of historical structural change (Bucar, Glas and Hisrich, 2003). Thus if in a society the meaning of short-term vs long-term entrepreneurship has been consolidated, then even if there are accumulated surpluses of resources via short-term entrepreneurship, they will never be transferred or they will be transformed into long-term entrepreneurship with great difficulty. The question is also related to the issue of the introduction of innovation. Generally speaking the development and introduction of innovation usually require substantial periods of time and risk taking behaviour. 


\section{THE ENTREPRENEURIAL TIME COMMITMENT AS A CULTURAL AND PERSONAL TRAIT}

According to Bird and Page (1997) the entrepreneurship engagement in the resources-time interface has at least three time elements: perception, anticipation and action (short term-tactical behaviours). Perception means 'to engage thoroughly' in the present. Anticipation denotes the future tense and touches on the possibilities of future states. Jaques (1997) outlines two dimensions of time related to anticipation: succession and intuition. The latter captures the complexity of moving forward in time. The size and value of the firm are fundamentally linked to the entrepreneur's intentions.

According to Shane and Venkataraman (2000) entrepreneurship also means the process by which opportunities to create future goods and services are discovered, evaluated and exploited. The individual according to his or her sensitivity alertness (Kirzner 1973, 1979) reacts to the information s/he receives and recognises the entrepreneurial opportunity. At that moment the entrepreneurial opportunities are continuously evaluated either within a formal or informal process (Timmons, Muzyka, Stevenson and Bygrave 1987).

Entrepreneurs develop their entrepreneurial alertness either on the grounds of backward or forward interpretation (Yu 2001) of incoming information and only to the level that they pace with their time preference. Entrepreneurial alertness is not a complete process but a unilaterally developed sensitivity which is biased in favour of short-terms actions. Note that in cases where a long-term perception of time prevails in society, then the long-term entrepreneurial trap can arise where no immediate results in entrepreneurial activity are taking place.

The final phase of the evaluation, by using time discount of future inflows, constitutes only part of the influence of the time preference on the process of entrepreneurship. Time preference is much more important in all previous stages of the process of opportunity, identification and development. Thus accidental discovery (Teach et al., 1989) is dramatically decreased. Moreover social networks (De Koning 1999, Lechner and Dowling 2003) are shaped under the influence of a specific perception of preference of time, which they also transmit to the candidate entrepreneur. Thus, they contribute to the reproduction of entrepreneurial opportunities which obey specific values of time (Anderson and Jack 2002).

The research concerning factors affecting entrepreneurial activity has a long history and extends into the fields of economics (Schumpeter 1934), sociology (Weber 1930), and psychology (McClelland 1961). Entrepreneurial activity is the combined result of macro level environmental conditions (Aldrich 2000), which have economic or social origin; the characteristics of entrepreneurial opportunities (Christiansen 1997), and of human behaviour related to entrepreneurial motives (Shane, Locke and Collins 2003) and cognitions (Mitchell, Smith et al. 2002).

The factors determined the entrepreneurial behaviour and especially the entrepreneurial behaviour towards risk may be distinguished in six main broad areas: the macro-environmental, the cultural idiosyncrasies, the cognitive variables, the entrepreneurial motives and the personal traits, the entrepreneurial demographic characteristics and finally the microeconomics of the project.

With the macro-environmental group of variables we may identify the following variables:

- $\quad$ Per capita income and higher rates of growth.

- $\quad$ The phase of business cycle.

- $\quad$ The nominal interest rates combined with inflation rate indicate the evaluation of time.

- Derman (2002) proposes an additional dimension of time in the traditional risk-return relationships when he creates a version of the capital asset pricing model.

- An entrepreneur who lives in an unstable economic environment will obviously show a higher preference for the present over the future.

- A non-investment budgetary deficit of central government is in itself a powerful signal, ceteris paribus, for the entire society about the preference for the present versus the future.

- $\quad$ The administrative burdens created by the operation of bureaucracy in terms of cost for the operation of firms are a serious factor that influences the process of evaluation of time (Baughn and Neupert 2003). 
- The legal framework of exploitation of entrepreneurial patents is one more factor which determinates the relationship between present and future.

- $\quad$ The conditions of the job market considerably influence the time horizon of an entrepreneurial idea.

- We should also give a great deal of attention to the more general geo-strategic and political factors of the entrepreneurial environment.

The most important cultural variables are the following:

- $\quad$ Since individualist values prevail in a society, we will accept the idea that there is no threat to long-term entrepreneurship and consequently the preference of the future over the present is favoured. Societies dominated by collectivist views have negative effects on the duration of entrepreneurial activities, because they usually do not promote the importance of individualist action.

- $\quad$ Societies that show low uncertainty avoidance usually have high confidence in the future.

- We could also accept that societies characterised by a high tolerance of social inequality accept higher values for entrepreneurial activities and a higher value for the future over the present

- $\quad$ Societies which are characterised by masculinity give more value to the future.

The role of religion has an important role in the consolidation of these situations. Western Christianity encourages every effort to improve the attribution of resources. Eastern Christianity speaks of provisional cession of earthly wealth to mortals from God (Economou 2003). The Moslem religion faces uncertainty, risk or speculation (charat) as prohibited values (Ariff 1988), but it encourages the realisation of commercial activity. One of the four basic principles of Confucius's teaching consists in trying to acquire skills and education, working hard, not spending more than necessary [my emphasis], being patient and preserving.

We can specify two more distinct sources which influence the entrepreneurial perception of time: personal characteristics and the specifics of the project. In the first category we should include the family situation; the age; the health and the educational level. The less the personal obligations, the younger the age, the better the health and the higher educational level may lead to preference for the future.

The specifics of the project include:

- $\quad$ The nature and the origin of the resources that are to be used. The higher the marginal value of the money unit, the higher is the preference for the present over the future.

- A financial structure based on devotion to high own capital creates conditions of higher preference for the present.

- $\quad$ The greater the size of the project, the greater the preference for the present.

- $\quad$ The sector in which the entrepreneur is working is very likely to influence his or her time preference. Entrepreneurs of entire sectors have preference for the present over the future.

- The payback criterion (preferably discounted) expresses the evaluation of time gives a proxy of the entrepreneur's possibility of disengaging from his or her investment.

The main cognitive factors are knowledge (industry, technology), skills (leadership, decision-making, planning etc.) and abilities (intelligence etc.) (Shane, Locke and Collins 2003). Cognitions may affect entrepreneurs' perception of time. When the businessperson possesses good knowledge of the industry, s/he knows with precision the ideal horizon of his or her entrepreneurial activity. In any case we generally accept that the more developed cognitive factors are, the more easily the entrepreneur may be willing to extend the time horizon of his or her entrepreneurial effort and the more s/he will value the future over the present.

The main entrepreneurial motives have been located as tolerance for ambiguity, locus of control, desire for independence, creativity and need for achievement. We could accept that the need for achievement is not related to the perception of time. A powerful locus of control drives the entrepreneur to accept a higher value for the future. Moreover the higher his or her tendency is for risk-taking, the less tolerance there is and the smaller the horizon of 
entrepreneurial activation, the greater the preference for the present. Finally creativity may have an ambiguous effect on the perception of time.

\section{ENTREPRENEURIAL RISK ATTITUDES}

Risk reflects the degree of uncertainty and potential loss associated with the outcomes which may follow from a given behaviour or a set of behaviours (Forlani and Mullins 2000). Yates and Stone (1992) identify the basic element of risk construction: potential losses and the significance of those losses. The point of research focuses on how entrepreneurs cope with the risks inherent in their decisions, what determines the way they perceive the riskiness of their decisions, whether they possess character traits which predispose them to engage in uncertain behaviour or whether they assess opportunities and threats differently from non-entrepreneurs (Norton and Moore 2002).

The expected utility theory found in psychology and information economics formed the basic theoretical background for the explanation of decision-making under risk. (Cherry and Fraedrich 2002). Prospect theory (Kahneman and Tversky 1979), where the individual is risk averse in the domain of gains and risk-seeking in the domains of losses, is an alternative theorisation.

In any case entrepreneurs' risk-taking decision is extremely complex (Ghosh and Ray 1994). This is quite an obvious conclusion and has been stated very clearly from Knight (1921) to Baird and Thomas (1985) with their contingency model of strategic risk-taking. According to their analysis key variables affecting risk-taking were:

- $\quad$ general social-economic, e.g. government regulation and technological change (Cooper and Schendel 1976).

- $\quad$ variables related to industry's characteristics, e.g. number of competitors (Bain 1968); number of suppliers and customers (Porter 1980); and mobility barriers (Fox, 1973).

- $\quad$ variables related to project characteristics, e.g.. life-cycle, payback periods and project size (Beaver, Kettler and Scholes 1970).

- $\quad$ variables related to characteristics of the decision-maker, e.g. age, experience, knowledge.

- $\quad$ characteristics of the problem under consideration, e.g. complexity, ambiguity, controllability (Vlek and Stallen 1980); probability of loss (Slovic 1967) and problem framing (Tversky and Kahneman, 1981).

Mac Crimmon and Wehrung (1986) have identified three common risk determinants: lack of time, lack of information and lack of control over alternative courses of action. These three elements affect the subjective perception of risk.

Sitkin and Weingart (1995) summarise the whole framework of risk decision in two main sub domains: outcome history and problem framing (Sitkin and Pablo, 1992) as mediated in two crucial entrepreneurial variables: entrepreneurial risk propensity and perception of risk. Problem framing refers to whether a situation is presented to decisions-maker as an opportunity or a threat. Outcome history is a person-situation interaction characteristic defined as the degree to which the decision-maker believes that previous risk-related decisions have resulted in successful or unsuccessful outcomes (Sitkin and Weingart 1995). Correspondingly risk perception is defined as an individual's assessment of how controllable that uncertainty is (Baird and Thomas 1985) and risk propensity is defined as an individual's current tendency to take or avoid risk.

The concept of meditation on risk perception has also been stated in the work of Keh, Foo and Lim (2002). Their model also recognises four independent variables (overconfidence, belief in the law of small numbers, planning fallacy and illusion of control) and two control variables (demographics and risk propensity). The researchers have been utilising the work of Simon, Houghton and Aquino (2000) who found that the significant relationships are illusion of control belief in the law of small numbers with risk perception (negative relationship). Illusion of control and belief in the law of small number affect uncertain decisions positively and risk perception negatively. The same authors identify that flexibility, optimism and risk propensity affect a decision-maker's tolerance of risk.

Derived from the above analysis is the fact that risk perception mediates the relationship between cognitive biases and decisions under risk. Although enough theorisation has been developed about these associations (Busenitz 
and Barney 1997, Cooper et al. 1988, Palich and Barney 1995) the question about how cognitive biases lead individuals to perceive different levels of risk in the same decision situation needs further classification. This is despite the empirical evidence on the role of overconfidence, illusion of control etc. produced by Simon, Houghton and Aquino (2000) mainly because those approaches are partial equilibrium approaches. In other words, when we study such a complex phenomenon it is very difficult to isolate the influences of even basic factors that influence the decision under risk. This point should be taken into account when we examine well-supported evidence (Brockhaus 1980, Masters and Meir 1988) that risk tolerance or ambiguity tolerance do not reside differently in entrepreneurs. However, there is a discussion (Ghosh and Ray 1997) that risk and ambiguity have different and distinguished effects on entrepreneurial behaviour and specifically that the presence of ambiguity accentuates the perception of risk.

One rather different approach to handling the risk examines the risk-taking behaviour in relation to performance and especially to declining entrepreneurial process (Wiseman, Bromiley 1996). Their basic model based on behavioural theory of the firm includes six basic variables: (a) performance, (b) slack (debt/equity), (c) aspirations, (d) expectations, and (f) size as a measure of evolution. They found that potential slack positively influences risk; recoverable slack and the difference between performance aspirations and expectations negatively influence risk whereas recoverable slack and risk negatively influence performance.

However the most promising, although most expected, finding of Wiseman and Bromiley (1996) research is that their results suggest a cyclical process of risk and performance. Declining performance increases the unprofitable risk undertaken much in turn increases the undertaken risk. Perhaps the reverse of causation is also valid, that is surprising performance reduces the unpredictable risk undertaken which will in turn further reduce the undertaken risks.

\section{TIME AND RISK}

The development of the decision-making investment process within the standard neoclassical model has shaped time into a simple, mono-dimensional factor of decision-making. (Barreto 1989).

When the process of evaluation is conducted in terms of excessive preference for the present over the future, very few or no entrepreneurial plans are going to materialise.

The inclusion of time can be connected with significant aspects of the growth process. Time is introduced by the dynamic models and therefore it brings up the issues of equilibrating vs. non equilibrating growth paths. Thus, disequilibrium based on growth can emerge. It is also related to convergence issues. However, according to the scope of the present paper the issue of time is related and defined as the ideal duration of entrepreneurial commitment. This concept is directly related to the structural prototype prevailing in space and time since it can distinguish between short-term entrepreneurship to long-term or future-oriented entrepreneurship (Das and Bing-Sheng teng 1997).

Decision risk is defined here, according to the extended Sitkin and Pablo (1992) definition, as the extent to which there is uncertainty about whether potentially significant (satisfactory) and/or disappointing outcomes of decisions will be realised. Thus, risk reflects the degree of uncertainty and potential loss associated with the outcomes which may follow from a given behaviour or set of behaviours (Forlani and Mullins 2000). Yates and Stone (1992) identify the basic element of risk construction: potential losses and the significance of those losses. The point of research focuses on how entrepreneurs cope with the risks inherent in their decisions, what determines the way they perceive the riskiness of their decisions, and whether they possess character traits which predispose them to engage in uncertain behaviour or whether they assess opportunities and threats differently from non-entrepreneurs (Norton and Moore 2002).

In order to do so, we should clarify the meaning of the two basic risk concepts: risk perception and risk propensity. Thus, risk perception is a subjective concept about the controllability of uncertainty (Sitkin and Pablo 1992, Bird and Thomas 1985). This subjective concept generally speaking is developed according to how the problems are framed (how the problem is presented to the entrepreneur, positively or negatively), the outcome history (Sitkin and Weingart 1995), the problem under consideration and the cognitive process of risk perception development. This concept could be connected with the general society's sense of uncertainty controllability as a 
social value and it is formed at a personal level. When we speak about low (high) risk perception we are referring to a situation where the individual believes the uncertainty of outcomes is highly uncontrollable (strong controllability). Risk propensity is defined as an individual's current tendency to take or avoid risks (Sitkin and Pablo 1992, Sitkin and Weingart 1995). It is a clear personal trait which can also be influenced by general social values (as they can influence all aspects of entrepreneurial behaviour).

Drawing and extending the work of Sitkin and Pablo (1992) and Forlani and Mullins (2000) we can imply that the entrepreneur's perception of risk and decisions involving risk are distinct and separate cognitive processes. Moreover the risk propensity is a separate cognitive process from risk perception. Following Sitkin and Weingart (1995) and in contrast with previous researchers (Derby and Keeney 1981) we do not consider risk propensity as a stable personal attribute. Thus, we employ a trait-based definition which is constructed as a cumulative tendency to take or avoid risks and can be changed as a result of experience. Risk and uncertainly is about future and therefore is about time. Thus it is generally agreed that time plays a crucial role in risk (Strickland, Lewicki, and Katz 1966). Researchers such as Vlek and Stallen (1980) observed that several risk behaviours are related to time and the notion of discounting in time.

Das and Bing-Sheng Teng (1997) analyse the interrelation of risk and time given that risk is inherently embedded in time. First they put forward the notion of the risk horizon differentiating short-range risk from longrange risk and examine the risk behaviour of entrepreneurs in terms of their individual future orientation in connection with their risk propensity.

Short-range risk refers to variations in outcomes in the near future, while long-range risk relates to the distant future (Drucker 1971). However, when people make decisions about the distant future they may be engaged in either low-risk or high-risk long-range risk behaviour. The same individual may well exhibit low-risk behaviour regarding long-range risk and high-risk behaviour regarding short-range risk or vice versa.

Thus Das and Bing-Sheng Teng develop different entrepreneurial types by employing their distinct risk behaviour in the short run and in the long run. They suggest that craftsman entrepreneurs can be identified by their short-range high risk behaviour, while opportunistic entrepreneurs can be identified by their long-range low-risk behaviour. Their distinction has received empirical support although the findings are far from conclusive (Woo, Cooper and Dunkelberg 1991). According to Smith (1776) a craftsman entrepreneur is characterised by narrowness in education, low social awareness and involvement and they do not offer innovative products. In contrast, an opportunistic entrepreneur is one who typically has breadth in education and training as well as high social awareness and who is involved in providing novel products/services.

It may appear in two cases that an entrepreneurial attitude cannot be developed: when short-range orientation and low-risk behaviour manifest in the same individual as well as when long-range high-risk behaviour also manifest in the same individual.

Does entrepreneurial risk attitude affect entrepreneurial time perception or vice versa? How distinct are the cognitive processes of development of risk attitude and time perception? So far we have seen a situation where the combination of the two attitudes produced particular types of entrepreneurial attitudes. The prevailing of long-lasting attitudes towards the formation of one or other type of entrepreneurship may affect the industrial structure permanently or at least for a long period of time. More interesting would be the case where the cognitive process of developing the risk attitude may affect the cognitive process of developing the perception of time. These interrelations may develop not only because the cognitive process may be interrelated but because of cultural and social economic factors which determine that the one process may affect the other.

The important point arises when we come to the type of interrelation. If for instance the correlation of the two types of behaviour is positive then there will be a tendency for risk-loving behaviour to be developed in parallel with long-term perception of entrepreneurial commitment which will have serious consequences on the type of entrepreneurial attitude behaviour since, as we have seen, a non-entrepreneurial behaviour is expected to be observed under these circumstances. The interrelation of risk and time attitudes can also affect the entrepreneurial intertemporal 
rate of substitution. Long-range and risk-loving entrepreneurship may be connected with large intertemporal rate substitution while short-range and risk-averting behaviour are connected with a small intertemporal rate of substitution.

Another important point arises as to how the cognitive process of time and risk attitude is developed in relation to entrepreneurial decision-making. In other words the important points are related to the way those attitudes interfere with the entrepreneurial opportunities identification and development. Following the alertness perspective where entrepreneurs may assess opportunities and threats based on a Bayesian probability (Norton and Moore 2002), differing assessments of prospective outcomes may be attributable to differences in prior information as they are filtered by the risk and time attitudes. Therefore time and risk consideration will not enter within entrepreneurial decision-making as any type of investment criteria but as particular types of cognitive attitudes towards the assessment of entrepreneurial decision-making. These attitudes are developed and embodied in entrepreneurial behaviour through a long-lasting procedure originating in the general economic environment as it is mediated by personal traits and cognitive factors.

\section{THE ENTREPRENEURIAL PERCEPTION OF RISK: THE FIELD RESEARCH}

The field research will be developed as follows. At first mention of the data we will describe the variables under consideration. Then we will present their basic descriptive statistics and the multiple interrelationships between future orientation, risk perception and risk propensity. Finally, the relationship between time and risk will be established.

\section{The Definitions And The Basic Findings}

The target variables are time perception (tp), risk perception (rper), and risk propensity (rpr). A questionnaire was created addressed to 120 entrepreneurs of the SMEs whose own capital was smaller than 10,000,000 Euros (EU definition of SMEs). The firms were chosen to represent the sectoral and side distribution of the Greek economy. Therefore the findings of the field research represent the time and space characteristics of Greek economy. The answers have been given by the entrepreneur or "the person in charge of the economical decisions" of the enterprise. The answers are based on the assumption that the rest of the factors that could influence the answer, apart from those involved in the question, remain stable. The questions mainly concern the time of payback period of the investment, its average ideal duration, the level of risk undertaken and the entrepreneur's ability and perception to avoid or confront difficult situations.

\section{Future Orientation, Risk Perception And Risk Propensity}

The theoretical relationship on ideal time commitment and risk can be examined in terms of risk perception and risk propensity. The conclusions which can be derived refer to different issues: the first is in terms of perception of the ability to control uncertainty and the second in terms of risk propensity. Figure 1 presents a taxonomy of the answers calculated in four quarters. Each quarter is defined according to average risk propensity and average time commitment. It can be seen that $29 \%$ of the entrepreneurs can be characterized as high averting with short-range time commitment; $19 \%$ of entrepreneurs will be characterised as risk-seeking with long-range time commitment.

$14 \%$ of the entrepreneurs can be characterised as craftsmen and $38 \%$ as opportunistic. However a serious critique can be levelled against this type of taxonomy. It is hard to accept that the quarters of entrepreneurs (craftsman, opportunistic) and non-entrepreneurs can be characterised by the average values of time perception and risk propensity. What is not entrepreneurial behaviour in terms of risk propensity has not been defined yet. The same is true in terms of time commitment. Although Figure 1 reveals some tendencies on how entrepreneurs can be classified, it does not have a definable character for each entrepreneur.

As a second step we employ the Granger Causality Test (Granger 1969) in order to identify causality relationship between the variables. 
Figure 1: Future Orientation And Risk Propensity

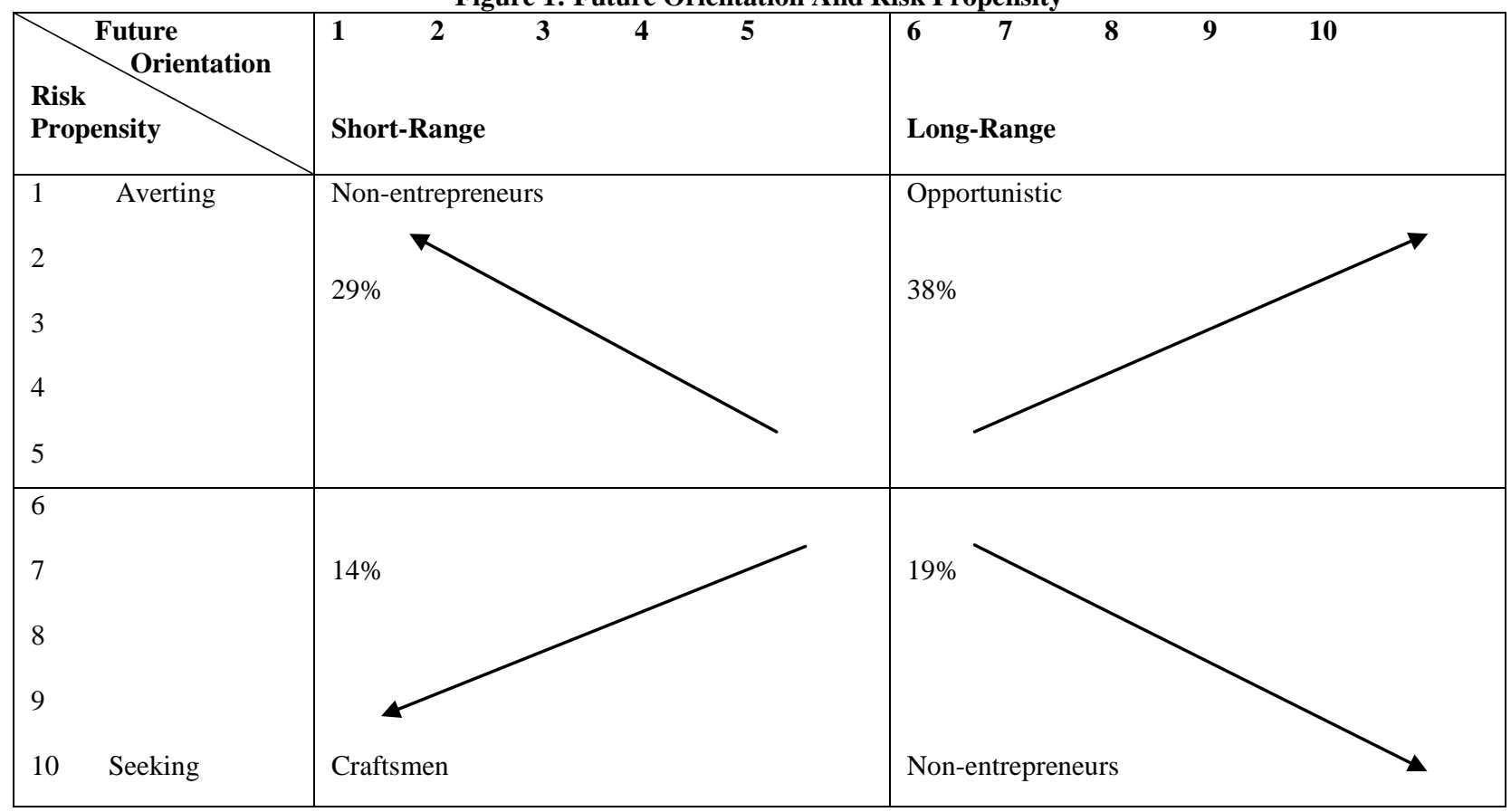

The first step for proceeding towards our conclusions is to test the stationarity of the time series we use. This is established using the Augmented Dickey Fuller (ADF) and the Phillips-Peron tests. Afterwards, we work on finding if there is a relationship between these series by testing their co-integration using the Johansen Co-integration Test. If we find some type of relationship between these series we use Granger Causality Test to check which series influences the other.

For the Granger Causality Test to function at all, it must first be determined whether the two series of data are stationary although co-integrated. If the series are non-stationary in the first levels, they are converted to stationary ones, with the formation of their first difference. Their co-integration is then measured by the Augmented Dickey Fuller (ADF) and the Phillips-Peron tests. If this two series of data are co-integrated, examining the function of integration according to Johansen, then they must constitute a relationship of causal connection at least in one direction (unidirectional causality) and possibly in two directions (bi-directional causality). The results of the Pairwise Granger Causality Tests are presented in Table 1.

Table 1: Pairwise Granger Causality Tests

\begin{tabular}{|l|c|c|}
\hline & F statistic & Probability \\
\hline tp does not Granger Cause rper & 0.399 & 0.671 \\
rperd does not Granger Cause tp & 5.140 & $0.007 *$ \\
\hline rpr does not Granger Cause rper & 0.654 & 0.521 \\
rper does not Granger Cause rpr & 0.959 & 0.386 \\
\hline rpr does not Granger cause tp & 0.043 & 0.957 \\
tp does not Granger Cause rpr & 0.097 & 0.907 \\
\hline
\end{tabular}

* Significant at $95 \%$ significance level.

Based on the above findings, in order to establish the empirical relationship of Time and Risk we perform a regression testing the above causality relationship. The results are represented below (Table 2). 
Table 2: Regression Results "pt" And "rper"

\begin{tabular}{|c|c|c|}
\hline \multicolumn{2}{|c|}{ Tp=0,60 rper } & $\bar{R}^{2}=0,36$ \\
\hline t-test & 8,10 & $R^{2}=0,59$ \\
\hline$($ Sig) & $(0,00)$ & Sig $\cong 0,00$ \\
\hline F=65,66 & & $\simeq$ \\
\hline
\end{tabular}

The findings are twofold. On the one hand they reveal that within entrepreneurial society as defined by the time and space elements of the field research there is quite large portion (approximately 50\%) of entrepreneurs with averting tendency who sport range time perception and risk-seeking behaviour and long range of time orientation. Both categories are not classified as the best type of entrepreneurial behaviour in return for entrepreneurial opportunities tracking and development. This finding may reveal one of the most crucial characteristics of the entrepreneurial sector (Greek economy). While it is forced to expand (35\% of the active populations is self-employed and there are 700,000 small and medium enterprises) at the same time it does not have adequate innovative introduction propensity (opportunistic behaviour). Therefore it cannot be transformed into a dynamic entrepreneurial opportunities environment. This evidence shows that we are facing an entrepreneurial sector which is created as a result of non-employment opportunities and less as a result of entrepreneurial-seeking opportunities.

Figure 2: Future Orientation And Risk Perception

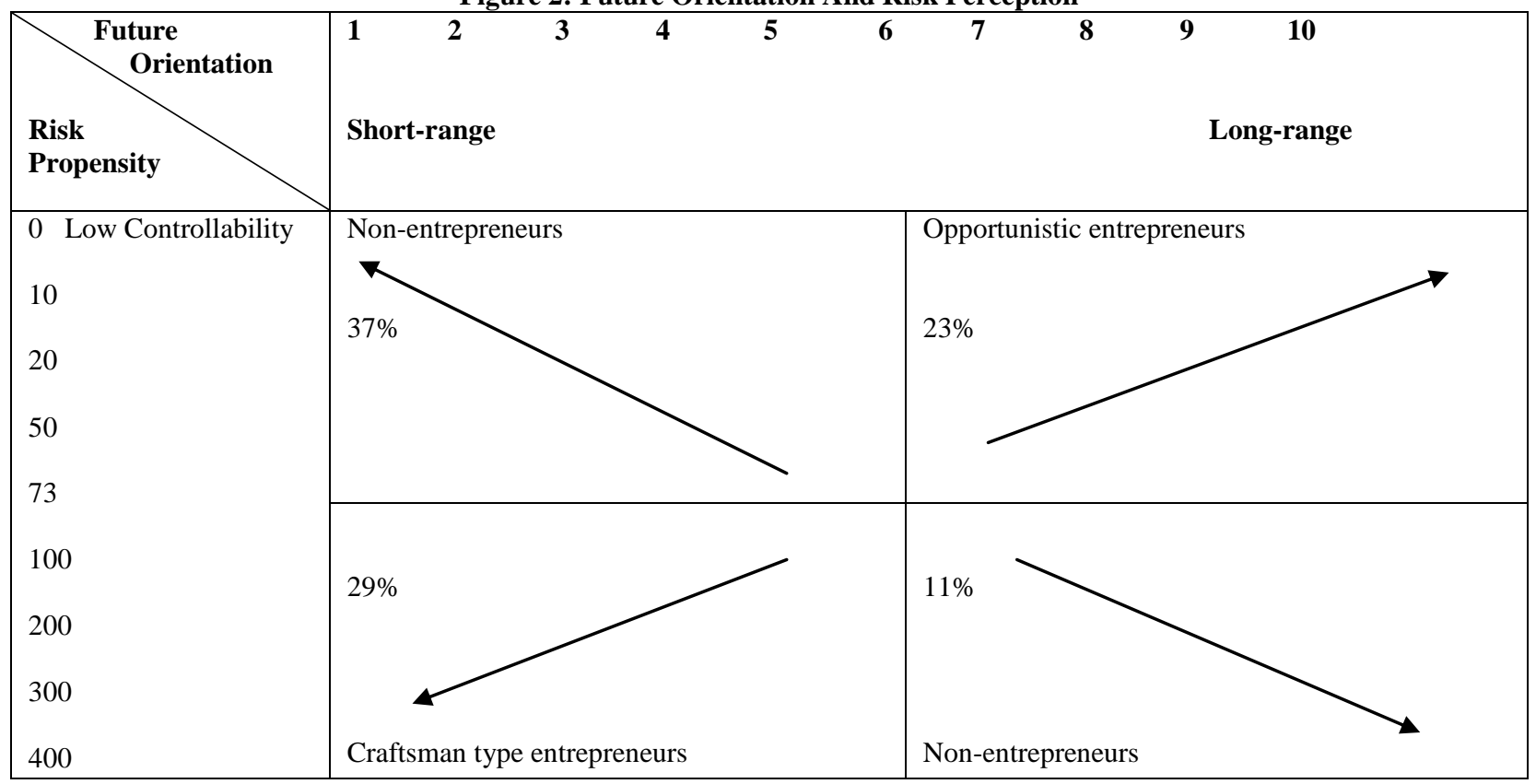

The second finding offers an adequate explanation for the first one. At the same time it reveals a basic characteristic of risk perception in comparison with the ideal time commitment. In other words, the perception of risk positively affects the development of entrepreneurial time perception in the form of an ideal entrepreneurial time commitment. The larger the perception of uncertainty controllability, the larger the acceptable time commitment. This is a finding which is logical and to be expected. Because a large portion of entrepreneurs exhibit low controllability and short-range future orientation (Figure 2) we may observe a situation where risk-averting behaviour is combined with short-range orientation. Similar conclusions may be drawn for the other combination of time and risk propensity. 
This conclusion is verified by the causality which is detected by the Granger Causality tests (Table 1). Therefore what we gain now is a reassurance that risk perception is a primary cognitive entrepreneurial characteristic of entrepreneurial behaviour and requires further investigation.

The above conclusion in relation to the findings of Simon et al. (2000), Hean Tat Kah et al. (2002) about the factors determining risk perception takes into account the whole framework of entrepreneurial risk behaviour and the entrepreneurial time commitment.

As for the field research outcome, in terms of entrepreneurial sector characteristics, it has been located as anti-entrepreneurial behaviour in terms of a relative strong tendency to exhibit risk-averting and short-range orientation and lower tendency towards risk-seeking, long-range entrepreneurship. This observation may reveal one of the most important weaknesses of the entrepreneurial sector from which the data originated.

\section{CONCLUSIONS}

This article has been about the relationship between risk perception, risk propensity and the ideal duration of entrepreneurial commitment.

As far as the risk attitude is concerned the paper also shows that the attempt to identify the factors determining the entrepreneurial behaviour towards risk reveals a framework of complicated interrelationships. This article is focused on risk perception or how the entrepreneur perceives his or her ability to control uncertainty. This characteristic contributes to the development of risk propensity and time perception in relation to the ideal duration of entrepreneurial commitment.

Two main points emerge: the way that risk is perceived by the entrepreneur is a primary cognitive procedure which determines other important aspects of entrepreneurial behaviour and performance. We found, within the limits of the present paper, no determining factors for risk perception; although it influences the way that cultural idiosyncrasies are formed, the way that knowledge and flexibility characteristics are developed and also affects company performance.

On the contrary risk propensity is determined within entrepreneurial behaviour, and mainly takes the mediating role of transforming influences from the external macroeconomic environment and some important personal traits. It also mediates the independence of the entrepreneur, his or her need for achievement and his or her risk perception.

The paper also deals with the issue of future orientation and risk propensity. Data originating from the questionnaire show that there are quite strong tendencies towards typical non-entrepreneurial behaviour within the entrepreneurial society from which the data was originated. In other words, risk-averting behaviour is often combined with short-range orientation and risk-seeking behaviour is sometimes combined with long-range behaviour.

The paper also shows that there is a causality relationship between risk and ideal average duration of timecommitment. This relationship has been confirmed by a regression where it was found that risk perception explains $36 \%$ of AIDEC variation. Thus, the stronger the risk perception the longer is the future orientation of the entrepreneur.

The findings of the paper have implications at both company level and the macro level (structural development issues) and consequently have significant policy implications. The understanding of risk perception formation will - to a certain extent - simplify understanding of the formation of the average time of entrepreneurial commitment. Both variables have in turn serious implications on the industrial structure prevailing in space and time. The industrial structure itself is affected and the entrepreneurial initiatives comply with specific characteristics. The case of short-term risk-averting behaviour which leads to non-innovative and eventually non-future-promising entrepreneurial behaviour can be the rule. These types of behavioural characteristics are embodied in entrepreneurial behaviour as a signalling screening process of incoming information as far as the selection of entrepreneurial activity and projects is concerned and thus affect the industrial structure. At the end of the day, what constitutes an ideal risk 
and time perception behaviour is an optimisation process where a number of influences with rather different origins have their own role. This last point will serve to launch a new research effort.

This type of entrepreneurial characteristic takes a long time to develop within the entrepreneurial attitude and it cannot usually be removed from it. It is more probable that this type of characteristic will be transformed to affect the industrial structure rather than being replaced by the opposite one. Thus, it is more probable that short-term risk averting behaviour may lead to a structural change from light industry to heavy industry rather than leading to longterm risk-averting behaviour.

This type of conclusion will make room for the development of particular industrial policies towards the promotion of industrial development. Thus, the limitations of measures towards transforming industrial structure in the short or medium term are obvious. Although, the effectiveness of policies towards reduction of risk is quite clear, according to the analysis developed in this direction, measures for improving the labour market flexibility and reducing political instability are to be welcomed. In any case a concrete build-up of policies measures can be specified according to the findings of the paper.

\section{BIBLIOGRAPHY}

1. $\quad$ Aldrich, H. 2000. Organizations Evolving. Beverly Hills: Sage.

2. Anderson, A. and Jack, S. 2002. The articulation of social capital in entrepreneurial networks: a glue of a lubricant? Entrepreneurship and Regional Development 14(3): 193-210.

3. $\quad$ Ariff, M. 1988. Islamic banking. Asian-Pacific Economic Literature 2(2): 46-62.

4. $\quad$ Bain J. S., 1968. Industrial Organization. New York: Willey

5. Baird I. S. and Thomas, H. 1985. Toward a contingency model of strategic risk taking. Academy of Management Review 10 (2): 230-243

6. Barreto, H. 1989. The Entrepreneur in Microeconomic Theory. London: Routledge Press.

7. Baughn, C. and Neupert, K. 2003. Culture and nation conditions facilitating entrepreneurial start ups. Journal of International Entrepreneurship 1: 313-330.

8. Beaver, W. H., Kettler, P., and Scholes, M. 1970. The association between market-determined and accounting - determined risk measures. Accounting Review 45: 654-682

9. Bird, B. J. and Page West, G. III. 1997. Time and entrepreneurship. Entrepreneurship Theory and Practice 22(2): 5-136.

10. Brockhaus, R. H., 1980. Risk taking Propensity of entrepreneurs. Academy of management Journal 23 (3): 509-520

11. Bucar, B., Glas, M., and Hisrich, R. 2003. Ethics and entrepreneurs: an international comparative study. Journal of Business Venturing 18: 261-281.

12. Busenitz, L. W. and Barney, J. B. 1997. Differences between entrepreneurs and managers in large organizations: biases and heuristics in strategic decision-making. Journal of Business Venturing 12: 9-30

13. Cherry, J. and Fraedrich, J., 2002. Perceived risk, moral philosophy and marketing ethics: mediating influences on sales managers' ethical decision-making. Journal of Business research 55(12): 951-962

14. Christiansen, C. 1997. The Innovator's Dilemma. Cambridge, MA: Harvard Business School Press.

15. Cooper, A. C. and Schendel, D. 1976 Strategic responses to technological threats. Business Horizons 19 (1): 61-69

16. Cooper, A. C., Woo, C. Y., and Dunkelberg, W. C., 1988. Entrepreneurs' perceived chances foe success. Journal of Business Venturing 3 (1):97-108

17. Das, T. K. and Teng, B. S. 1997. Time and entrepreneurial risk behavior. Entrepreneurship Theory and Practice 22 (2): 69-88.

18. De Koning, A. 1999. Conceptualizing Opportunity Recognition as a Socio-Cognitive Process. Stockholm: Centre for Advanced Studies in Leadership.

19. Derby, Stephen L. and Keeney, Ralph L. September 1981. Risk Analysis: Understanding 'How Safe is Safe Enough?' Risk Analysis 1 (3): 217-224.

20. Derman, E. 2002. The perception of time, risk and return during periods of speculation. Quantitative Finance 2: 282-296. 
21. Drucker, P. F. 1971. What we can learn from Japanese management. Harvard Business review 49 (2): 110122.

22. Economou, H. 2003. The Orthodox Christian concept on wealth and labour, Department of Theology, Discussion Paper, University of Athens.

23. Forlani, D. and Mullins, J. W., 2000. Perceived risks and choices in entrepreneurs' new venture decisions. Journal of Business Venturing 15: 305-322.

24. Fox, H., 1973. A framework for functional coordination. Atlanta Economic Review 23 (6): 10-11

25. Geletkanycz, M. A. 1997. The salience of culture's consequences: the effects of cultural values on top executive commitment to the status quo, Strategic Management Journal 18(8): 615-634.

26. Ghosh, D. and Ray, M. R. 1997. Risk, ambiguity, and decision choice: some additional evidence. Decision Sciences 28 (1): 81-104

27. Gomez-Mejia, L. R. and Balkan, D. B., 1989. Effectiveness of Individual and Aggregate Compensation Strategies. Industrial Relations 28(3): 431-445.

28. Granger, C. W. J. 1969. Investigating causal relations by econometric models and cross-spectral methods. Econometrica 37: 424-438.

29. Hayton, J., George, G., and Zahra, S. 2002. National culture and entrepreneurship: a review of behavioral research. Entrepreneurship Theory and Practice 26(4): 33-52.

30. Hean Tat Keh, Maw Der Foo, and Boon Chong Lim, 2002. Opportunity Evaluation under risky conditions: the cognitive processes of entrepreneurs. Entrepreneurship theory and practice 27 (2): 125-148.

31. Hofstede, G. 1993. Cultural constraints in management theories. Academy of Management Executive 7: 8194.

32. Jaques, E. 1997. Introduction to special issue on time and entrepreneurship. Entrepreneurship Theory and Practice 22(2): 11-12.

33. Kahneman, D. and Tversky, A., 1979. Prospect theory: an analysis of decision under risk. Econometrica 47: 263-291

34. Kirzner, I. M. 1973. Competition and Entrepreneurship. Chicago: University of Chicago Press.

35. Kirzner, I. M. 1979. Perception, Opportunity and Profit. Chicago: University of Chicago Press.

36. Knight, F. H., 1921. Risk, Uncertainty and Profit. Houghton Mifflin, New York.

37. Lechner, C. and Dowling, M. 2003. Firm networks: external relationships as sources for the growth and competitiveness of entrepreneurial firms. Entrepreneurship and Regional Development 15(1): 1-26.

38. Locke, E. A. 2000. Motivation, cognition and action: an analysis of studies of task goals and knowledge. Applied Psychology: An International Review 49: 408-429.

39. MacCrimmon, K. R. and Wehrung, D. A, 1986a. Taking risks: The management of uncertainty. New York: Free Press

40. Masters, R. and Meier, R. 1988. Sex differences and risk-taking propensity of entrepreneurs. Journal of small business management 26 (1) 31-35.

41. McCleland, D. C. 1961. The Achieving Society. Princeton, NJ: Van Nostrand.

42. Mitchell, R., Smith, B., Morse, E., Seawright, K., Peredo, A., and McKenzie, B. 2002. Are entrepreneurial cognitions universal? assessing entrepreneurial cognitions across cultures. Entrepreneurship Theory and Practice 26(4): 9-32.

43. Norton, W. I. and Moore, W. T. 2002. Entrepreneurial risk: Have we been asking the wrong question? Small business economics 18 (4): 281-287

44. Palich, L. E. and Barney, D.R. 1995. Using cognitive theory to explain entrepreneurial risk-taking: Challenging conventional wisdom. Journal of Business Venturing 10 (6): 425-438

45. Porter, M. E. 1980. Competitive strategy: Techniques for analysing industries and competitors. New York: Free Press.

46. $\quad$ Rice, R. and Kelly, J., 1997. Doomsday Risk, Financial Times, 4 p. 13.

47. Rowe, D. C. 1997. Genetics, temperament, and personality. In R. Hogan, J. Johnson, \& S. Briggs (Eds.), Handbook of personality psychology (pp. 369-386). San Diego, CA: Academic Press.

48. Schneider, S. L. 1992. Framing and conflict: Aspiration level contingency, the status quo, and current theories of risky choice. Journal of Experimental Psychology: Learning Memory and Cognition 18: 10401057.

49. Schumpeter, J. 1934. The Theory of Economic Development. Cambridge, MA: Harvard University Press. 
50. Shane, S. and Venkataraman, S. 2000, The promise of entrepreneurship as a field or research. Academy of Management Review 25(1): 217-226.

51. Shane, S., Locke, E., and Collins, C. 2003. Entrepreneurial motivation, Human Resource Management Review 13(2): 257-279.

52. Simon, M., Houghton, S. M., and Aquino, K. 2000. Cognitive biases, risk perception, and venture formation: How individuals decide to start companies. Journal of Business Venturing, 15: 113-134.

53. Sitkin, S. B. and Pablo, A., 1992. Reconceptualizing the determinants of risk behaviour. Academic Management Review 17: 9-38

54. Sitkin, S. B. and Weingart, L. R., 1995. Determinants of risky of decision-making behavior: A test of the mediating role of risk perception and propensity. Academy of management Journal 38 (6): 1573-1592

55. Slovic, P., 1967. The relative influence of probabilities and payoffs upon perceived risk of a gamble. Psychonomic Science 9:223-224

56. Smith, A., [1776] 1937. An inquiry into the nature and causes of the wealth of nations. New York: Modern Library.

57. Strickland, L. H., Lewicki, R. J., and Katz, A. 1966. Temporal orientation and perceived control as determinants of risk taking. Journal of experimental social psychology 2: 134-151.

58. Teach, R. D., Schawartz, R. G., and Tarpley, F.A. 1989. The recognition and exploitation of opportunity in the software industry: a study of surviving firms: In Frontiers of Entrepreneurship Research. R. H. Brockhaus, W. C. Churchill, J. Katz, B. A. Kirchhoff, K. H. Vesper and W. Wetzel, ed. Wellesley, MA: Babson College, pp. 383-397.

59. Timmons, J. A., Muzyka, D. F., Stevenson, H. H., and Bygrave, W. D. 1987. Opportunity recognition: the core of entrepreneurship. In: N.C. Churchill et al., eds., Frontiers of Entrepreneurship Research. Wellesley, MA: Babson College 109-123.

60. Tversky, A. and Kahneman, D. 1981. The framing of decisions and the psychology of choice. Science 211: 453-458.

61. Vlek, C. and Stallen, P. J., 1980. Rational and personal aspects of risk. Acta Psychologica 45:273-300

62. Wallach, M. and Kogan, N. 1964, Aspects of judgment and decision management: interrelationships and changes with age, Behavioral Science, 6(2): 23-26.

63. Weber, M. 1930. The Protestant Ethic and the Spirit of Capitalism. New York: Scribners.

64. Wiseman, R. M. and Bromiley, P. 1996 Toward a model of risk in declining organizations: An empirical examination of risk, performance and decline. Organization Science, 7: 524-543.

65. Woo, C. Y., Cooper, A. C., and Dunkelberg, W. C. (1991) The Development and Interpretation of Entrepreneurial Typologies, Journal of Business Venturing, 6(2):93-111

66. Yates, F. and Stone, E.R. 1992. The risk construct. In Yates F. (ed) Risk-Taking Behaviour. John Wiley \& Sons: 1-26

67. Yu, T. Fu-Lai. 2001. Entrepreneurial alertness and discovery. Review of Austrian Economics 14(1): 47-63. 


\section{NOTES}

